\title{
Generic Supply Chain of Lean-Value Stream Mapping in Automotive Industry
}

\author{
D Chandrasekar, P. Kumaran
}

\begin{abstract}
Nowadays automobile industry, as manufacturers structure and construct vehicles all-inclusive, their supply chains become progressively perplexing with difficulties in the method of profitability and investor worth value such as excess inventory over the production network and absence of permeability of providers. So as to expand the aggressiveness of the automotive industry with store network, here lean administration idea is incorporated as lean supply chain management (LSCM).The Lean supply chain is utilized to streamline the business forms by wiping out waste and non-value added activities. The association between lean and SCM is one of the techniques for expense and time decrease to improve the viability. The lean supply chain is likewise centered around advancing the procedure of all production network and scanning for rearrangements. This research paper is proposed a lean supply chain managementvalue stream mapping (LSCM-VSM) is utilized to dispense with waste and improved operational methodology and efficiency. It is a procedure of envisioning mapping stream of information and producing the future-state map with better strategies and execution. The exploratory outcomes demonstrate the production lead time (PLT) by executing the proposed LVSM and future more assesses the total cycle time (TCT) and value-added ratio(VA\%) of a value stream.

Keywords: Supply chain, Lean Supply Chain, Value Stream Mapping, Production lead time, current state map, Future state map.
\end{abstract}

Generally, the automotive industry is main driver improvement of a nation's money related framework and is an extensive provider to the overall economy. The automobile is characterized as 'both a structure and capacity' on the item including an abnormal state of designing just as being situated as an item. The automotive industry is applicable as far as its effect on the country just as on innovation. The automotive sector is worldwide and is characterized as a capital-intensive industry with vertical integration and economics of scale. It has been in charge of the improvement of mechanical development and the board and the first significant change in the modern generation forms.

The lean ideas and supply chain management are lead to a development termed lean supply chain (LSC) and that improves execution. The observing, estimating and improving execution is basic to the achievement of an LSC that add to discover improvement openings and decide essential activities. The Lean is a systematic methodology that focuses on improving superiority, rate and conveyance by dispensing with a wide range of waste, make stream and increment the framework ready to satisfy client need.

Revised Manuscript Received on December 30, 2019.

D Chandrasekar, Department of Mechanical Engineering, Saveetha School of Engineering, SIMATS, Tamil Nadu, Chennai of Engineering, SIMATS, Tamil Nadu, Chennai

\section{I.INTRODUCTION}

P. Kumaran, Department of Automobile Engineering, Saveetha School

The expression of "supply chain management" was initially presented in the mid- 1980s. The enormous organizations found that SCM isn't adequate to improve execution just inside the association. The lean related systems and instrument are connected all through the supply chain that structures as LSC and gives colossal chances to assist improvement in each part and furthermore in the inventory network in general. The target of an LSC is expanding profitability by applying lean so as to take out waste and make it compelling and effective enough to fulfill all inventory network individuals. The exhibition estimation appraises the present introduction so as to perceive the chance to manufacture noteworthy enhancements and subsequently expanding proficiency and efficiency. On account of lean, there are three ways to deal with measure its exhibition. The first is estimating the level of execution of lean devices and systems. The second is subsequent way to deal with lean assessment is estimating execution yields because of lean usage. In this unique circumstance, cost, quality, conveyance and unwavering quality (C\&W), adaptability and constant improvement got the most consideration. The third methodology in lean assessment is a blended method of the first and second approaches. At the end of the day in this methodology, both lean apparatuses usage and execution viewpoints will be considered and totaled in a bound together list. The supply chain has been perceived as a key factor of accomplishment and one of the incredible methods by which organizations can accomplish an objective of significance is to upgrade consumer loyalty.

It is important to think about the value and value a stream is. The value is centered around the setting of what the client or end-client is set up to pay for. To complete this action the organization needs to comprehend what the client requires as far as highlights and execution and the amount they are willing to pay for the item. The result of this action is a reasonable comprehension of the item the client requires. The value stream characterizes the entire creation process for an item. It begins at the idea and closures at conveyance to the client. Each phase of the item increase the value of the item and it is regularly is not the situation. Mapping of the value stream helps the recognizable proof of significant value including and non-value including exercises.

VSM has envisioned the station process durations, stock at each stage, labor and data stream over the production network. VSM empowers an organization to see the whole procedure in both the present and future express that builds up the guide to organize the activities to conquer any hindrance between the present state and the future state. A few advantages are 
Allow a wide perspective on the whole stream and recognizes squanders;

- Shows the connection between material and data stream;

- Provides a straightforward and institutionalized approach to treat Procedures

The value stream is overseeing includes a procedure of getting, estimating and improving the progression of materials and data and the connection of the considerable number of undertakings. It is utilized to make, program and produce an item that can't be estimated and can't be unequivocally distinguished, broke down, addressed and at last improved. It is one of the significant apparatuses for current procedure status and improving chances. It is a helpful apparatus for managing upgrades dependent on painstakingly considered and created a plan.

\section{AUTOMOTIVE SUPPLY CHAIN}

The automotive industry is comprised of supply the executives and physical conveyance the board. The business production network extends from the makers of crude materials through to the gathering of the most complex electronic and registering advancements. The significant part of the store network incorporates providers (level 1 - 3), OEMs, dissemination centers, vendors, clients.Most car OEMs make 30 to $35 \%$ of significant worth inside and delegate the rest to their provider. Makers acquired whole subassemblies, for example, entryways, control trains, and hardware from providers. The craving to work with accomplices to re-appropriate subassemblies is prompting a fundamentally new framework to help them plan, acquirement, and coordinations procedures of the makers. It understand that to improve their creative capacity, get autos to showcase quicker and decrease mistakes, carmakers need to improve their advancement and the board capacities through advances in computer-aided design (CAD), computer-aided procedure arranging (CAPA), computerassisted manufacturing (CAM), computer-aided engineering (CAE), concurrent engineering (CE), product data management (PDM), business process engineering, and so on.

\section{ADVANTAGES OF LEAN SUPPLY CHAIN}

\section{Decreased expense and improved conveyance}

Squander disposal that stays away from overgeneration, pointless transportation, stock, and handling.

\section{High caliber}

Consistent issue search TPM, VSM representative association, visual control, and factual quality control, provider inclusion in the early structure stages.

\section{Low inventories}

In the just in time and force generation and consequently stock expenses

\section{Consumer loyalty}

Distinguishing esteem including exercises and worth chain examination for the accomplishment of consumer loyalty

High adaptability (volume, item blend, and conveyance)

Little size, compelling correspondence, and data sharing.

\section{Advanced productivity \\ Constant issue search, TPM, VSM and}

The remainder of this proposed work is delineated as pursues. In Section II depicts related works about lean supply chain of value stream mapping in automotive industry.. The proposed strategy execution is clarified in section III. Section IV displays the trial results. Section V bargains the end.

\section{II.RELATED WORKS}

Ana Julia Dal Forno et al(2014) Value stream mapping (VSM) is a significant instrument of the lean methodology and is utilized to distinguish esteem including exercises and that thought about inefficient of materials and the progression of data and individuals. The reason for this paper is to examine the principle challenges and constraints experienced during the development of current state maps, an examination of the related causes, and calling attention to of rules to encourage the utilization of VSM to guide forms. To do as such, a hunt and assessment of papers in diaries, meetings, postulations, and papers were directed, and the articles were arranged by the field of use (processing plant floor, inventory network, item improvement, and administrations) and approach (hypothetical or viable). All in all, this paper scrutinizes a few different ways that VSM has been utilized, seeing that significant limitations made by its application must be considered and that when utilized erroneously, the device can prompt mix-ups that can cause issues rather than advantages. Considering the issues recognized, the paper proposes future works for improving the utilization of VSM for mapping forms. Haifa Aby Nimeh et al (2018) To examine the impacts of lean production network the board (LSCM) rehearses on store network execution and market execution of assembling organizations in Jordan. Five LSCM practices were recognized dependent on a broad writing survey, in particular, in the nick of time framework, the stream of data, provider relationship, client relationship, and waste decrease. To accomplish the investigation objectives, a study survey was arranged and dispersed to chiefs of 400 assembling organizations from various businesses and sizes. The last number of usable polls was 308 , speaking to a reaction rate of $77 \%$. The outcomes uncovered positive and critical impacts of three LSCM rehearses on market execution, in particular, in the nick of time framework, the stream of data, and client relationship. Moreover, all LSCM practices demonstrated positive and huge impacts on inventory network execution. Moreover, inventory network execution exhibited a positive and critical impact on market execution. Egon Müller et al(2014)In the business, Lean Production Systems have been effectively utilized for a considerable length of time to lessen lead times. The worth stream mapping strategy (VSM) has demonstrated itself to be the best practice instrument for this reason. With this technique, procedure steps can without much of a stretch be isolated into worth including and non-esteem including ones.

representative contribution. 
Be that as it may, the VSM does not give any data about the creation procedure vitality utilization and, as an outcome, it doesn't give any allude to the amount of the vitality utilized really fills esteem including needs. Likewise, transportation and coordinations have not been broken down by their time-and vitality productivity up to now. Would it be realized how much vitality is utilized for worth including and for essential procedure steps, at that point, it is conceivable to advance worth streams in a comprehensive manner, at the same time thinking about time-and vitality utilization. This paper portrays how the VSM can be reached out to a vitality esteem stream mapping technique (EVSM) by keeping up its unique character and its internal rationale. Moreover, transportation forms and the related time and vitality info have been added to the EVSM.

Bhim Singh et al (2011) Value stream mapping (VSM) is a lean assembling method and it has risen as the favored method to help and execute the lean methodology. VSM is not quite the same as regular chronicle strategies, as it catches the data at individual stations about station process duration, uptime or usage of assets, set-up time or change after some time, work in procedure stock, labor prerequisite and the data stream from crude material to complete merchandise. It covers both worth including just as non-esteem including exercises. This paper covers the audit and grouping of writing on VSM, as there is not really any paper on writing survey of VSM, so it will be extremely recipient for both academician and industry individuals.

Boppana V. Chowdary et al(2017) The motivation behind this paper is to give an understanding of the use of adaptable lean devices to a nearby organization for the rebuilding of the assembling activities. The investigation helps directors in the documentation of the worth streams, to endeavor constantly for flawlessness and to guarantee adaptability in the rebuilding of their assembling activities. To lead the examination, both subjective and quantitative methodologies were pursued. In recording worth stream map (VSM), a center gathering of workers from generation, coordinations, and stockroom divisions were included. The important information was gathered through meetings and field visits. For the development of the framework, lean apparatuses, for example, $5 \mathrm{~S}$, one-piece stream and electronic data framework (EIS) have been proposed. The lean usage in the chose to assemble organization yielded squander decrease because of wrong preparing (39\%), decrease indefinite stock $(70 \%)$, decrease in floor zone $(45 \%)$, decrease in labor (half), decrease in process duration (48\%), decrease in WIP stock $(83 \%)$, and decrease in non-esteem included time $(60 \%)$. The adaptable lean apparatuses suggested in this examination can bolster experts in improving both generation proficiency and adaptability in the rebuilding of assembling activities.

I. M. Ambe et al(2010) The changing business states of the 21 st century has prompted organizations confronting issues going from globalization, financial vulnerability to new advancements and expanding shopper requests. The nonexclusive store network procedures are lean and lithe inventory network. While leanness is most suitable to be utilized in a steady and unsurprising condition, readiness can accomplish more advantages in an unstable and unexpected condition. The leanness worldview gives more consideration to the minimal effort, high caliber and is progressively centered around innovation and frameworks. Despite what might be expected, the spryness may put higher accentuation on the adaptability and brisk conveyance to the clients. A spry maker needs to keep up a specific level of cradle ability to adapt to the unstable interest and high assortment of items and is centered around individuals and data. Besides, the paper proposes a system for leagile store network for the vehicle business. Utilization of the system would guarantee cost minimization and simultaneously react to the client request.

Lakri Siham et al(2015)present exploratory research demonstrating the assortment and the interrelationships highlight of the difficulties to structure a performant SC PMMS. At that point, we proposed a fundamental based technique to help in the planning procedure of a performant SC PMMS or help in the appraisal and investigation of the exhibition of a current framework. The qualities of the technique portrayed are for the most part the ability to consider the SC PMMS as a mind-boggling framework, to recognize key qualities expected, to guarantee their vigorous creation, and to feature the connections of reliance among qualities and assets by means of the elaboration of procedures. Also, this technique could be utilized to deal with the advancement of the framework structure and to pursue its presentation.

\section{III.III PROPOSED METHODOLOGY}

The supply chain management is extended the lean supply chain process and value stream mapping tool is used to reduce the waste and increased productivity cost and VSM is categorized into current and future state map. Production lead time (PLT), total cycle time (TCT) and value-added ratio (VA \%) are used to calculate the VSM.

Flowchart of proposed Methodology 


\section{Generic Supply Chain of Lean-Value Stream Mapping in Automotive Industry}

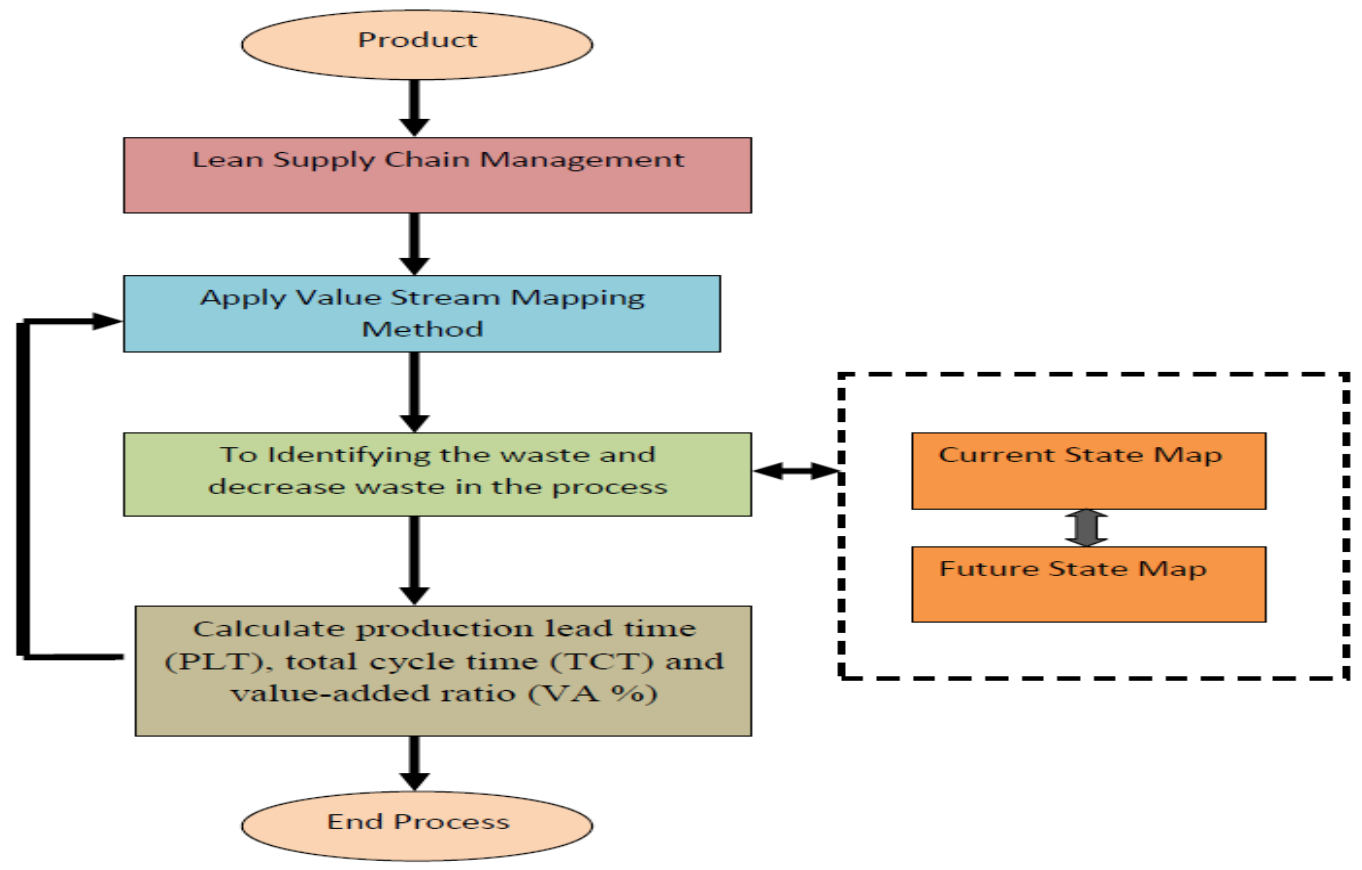

Figure 1 Flowchart of Proposed Methodology

\section{LEAN SUPPLY CHAIN MANAGEMENT}

It is a set of organization straightforwardly interconnected by upstream and downstream progressions of items, administrations, accounts and data that cooperatively work to decrease cost and waste by productively and successfully the requirements of the individual client. A lean production network configuration necessitates that supply chains limit the expense of activity at whole levels. Lean necessitates that the production network utilizes a minimal measure of assets to effectively finish its activity. It negligible inventories in the framework, insignificant measure of warehousing space required to store their inventories and enhanced to diminish the expense of moving stock. The lean inventory network lessens the expenses of the production network tasks, making it amazingly costeffective that additionally oblige the supply chains capacity to adjust to any adjustments sought after, supply or different assets because of the structures. It represents a new way of creating about network. The adjusting collaboration and rivalry are the standards require agreeable provider connections. The key element of lean production network the board is provider organizations and coordination components. The term lean supply infers that store network is fitting for lean creation.

Lean supply chain the executives' standards are the fundamental Lean standards

It is center around the provider system value stream

- It disposes of waste and synchronizes pursue, limits both exchange and creation costs.

- It builds up joint effort interconnection with adjusting participation and rivalry.

- It guarantees permeability and straightforwardness and grows snappy reaction ability

- It forms provider joining into plan and improvement, oversee vulnerability and hazard.

\section{Table 1 Shows the Lean and Supply Chain Comparison}

\begin{tabular}{|l|l|}
\hline Lean Supply Chain & Supply Chain Management \\
\hline It reduces waste and non value included activities. & $\begin{array}{l}\text { The objective is diminished lead cost through } \\
\text { different strategies }\end{array}$ \\
\hline $\begin{array}{l}\text { By and large, centered around progress with for the } \\
\text { most part streamlining shop floor }\end{array}$ & $\begin{array}{l}\text { Generally centered around advancement crosswise } \\
\text { overproduction network accomplices. }\end{array}$ \\
\hline Utilizations a lot of organized tools & $\begin{array}{l}\text { Applies lean apparatuses just as utilizing different } \\
\text { instruments like six sigma, TQM, TOC and limiting } \\
\text { stock through different systems. }\end{array}$ \\
\hline
\end{tabular}

Figure. 2 indicates the design development inventory network. Significant alteration is of how parts in a framework and item are connected together. Critical improvement in framework/item engineering is through changes in structure, utilitarian interfaces or framework design. Learning combination over the provider system has worth stream point of view. 




Figure 2 Architecture Innovation of Supply Chain Management

\section{STANDARDS OF LEAN SUPPLY CHAIN \\ MANAGEMENT}

Seek a strategic customer value focus

- Communication and web advancements have prepared the clients to utilize worldwide markets

- Lean standards connected in the inventory network straightforwardly sway the worth given by the item and by the store network to a conveyance of item.

Seek Single sources and Reliable providers

- A small number of providers prompts more reliance among them and it understands the inability to convey.

- Reliability works in the two different ways in LSCM: providers ought to have auspicious correspondences and tackle issues and satisfy client need issues that organizations face and try to set up a long haul relationship.

Seek a Demand Pull, Coordinated supply chain

- Coordinating the supply chain sought after a draw and each production network is shown as a client. The key is to deal with each accomplice of the interesting pull so least time is expected to process the interest demand.

- $\quad$ By pulling the interest that is made and conveyed in the store network to create the item into the expended item without waste and it will be synchronized production network and effective waste expulsion.

\section{Value Stream Mapping}

The value stream mapping is the first time a procedure showed up on the scene that was able for handy use and made it conceivable to take a gander at the process duration independently from the non-esteem including lead time. This strategy is separating the procedures of a worth stream into the two classifications value-including and nonvalue including. In this methodology, limiting the lead time was in the focal point of their advantage. The creation leads time with the whole of the process durations which they called handling time. It has appeared in figure 2 underneath and this takes Toyota Production framework for instance and assesses the generation lead time and preparing time. 


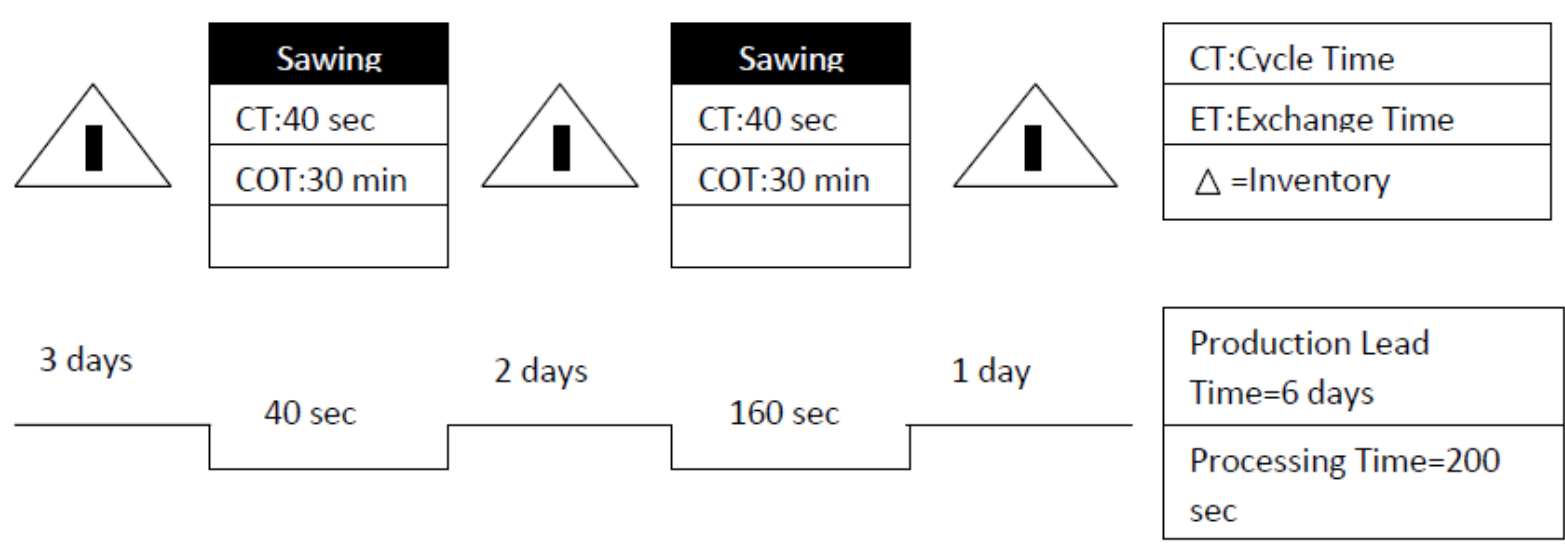

\begin{tabular}{|c|c|c|c|c|c|c|c|c|}
\hline \multirow[t]{2}{*}{$t_{\text {nva }}$} & & & \multirow[t]{2}{*}{$\mathrm{t}_{\mathrm{nva}}$} & & & $\mathrm{t}_{\text {nva }}$ & \multicolumn{2}{|c|}{$\Sigma t_{n v a}$} \\
\hline & $\mathrm{t}_{\mathrm{va}}$ & $\mathrm{t}_{\mathrm{nva}}$ & & $t_{\text {va }}$ & $t_{\text {nva }}$ & & $\Sigma t_{v a}$ & $\Sigma t_{n v a}$ \\
\hline
\end{tabular}

$\mathrm{t}_{\mathrm{va}}=$ time value-adding $\quad \mathrm{t}_{\mathrm{va}}=$ time non value-adding

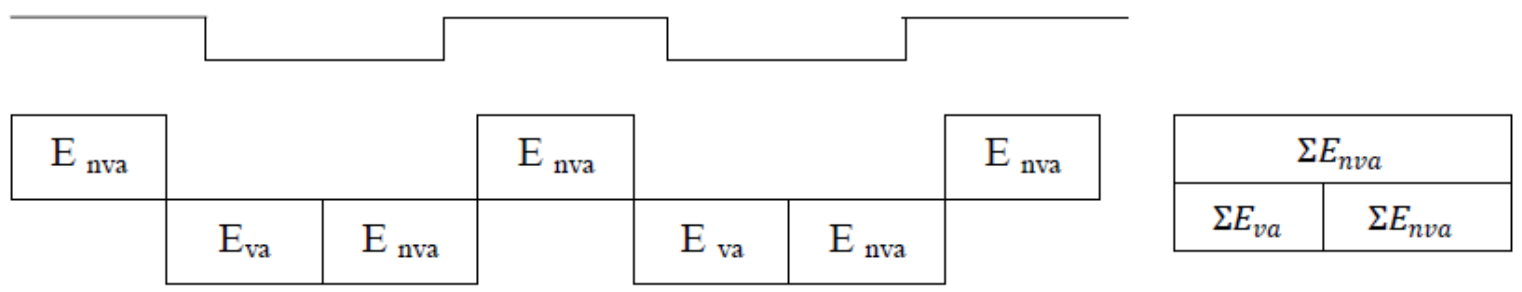

$\mathrm{E}_{\mathrm{va}}=$ time value-adding $\quad \mathrm{E}_{\mathrm{va}}=$ time non value-adding

Figure 3 VSM according and schematic representation of value-adding and non value-adding input of time and energy

\section{LSCM-VSM Method}

It is proposed to condense lead time in the automotive industry. The first step is to choose the item by applying item-capacity analysis (I-C analysis). It subdivides entire items into process cluster. The item clusters are prioritized concerning to their quantity.

The second step of LSCM-based VSM strategy to outline the current state of a value stream. The present state guide plans to find value and non-value included activities. It assesses the terms of succession time (ST), exchange time (ET), available production time (AT) and uptime (UT). These presentations are characterized and defined as pursues

Firstly, the definition of ST is the actual time required to make a product. It can be calculated by the ratio of size to processing time

\section{ST=Processing time/Batch Size}

Secondly, the ET is characterized as the time required exchanging item units on a machine

ET=Time past between the last piece in the run and the principal best piece after the trade.
Thirdly, the AT methods the time spent to add esteems to the item inside one day. It relates working time, idle time, maintenance time and others.

AT $=$ working time-inactive time-upkeep timeothers

Fourthly, the UT is characterized as the extent of time spent on a machine to embed an incentive to items and accessible creation time

\section{$\mathbf{U T}=(\mathbf{A T}-\mathbf{E T}) / \mathbf{A T}$}

Finally, the TT alludes to the time required to add esteems to an item requested by customers. It is determined by the proportion of production time to the client request.

\section{$\mathbf{T T}=\mathrm{AT} /$ Customer demand}

While these conditions are utilized to assess the exhibition of generation singular exercises. The exhibition markers are computed the creation lead time(PLT), total cycle time(TCT) and worth included proportion of a worth stream for the inventory network covering exercises from material conveyance from providers to item conveyance to clients. 
PLT is characterized by the time taken to make an item along a value stream. It is determined generation lead time everything being equal

$$
\mathrm{PLT}=\mathrm{LT}_{1}+\mathrm{LT}_{2}+\mathrm{LT}_{3}+\ldots . \mathrm{LT} \mathrm{T}_{\mathrm{n}}
$$

TCT is characterized by the real-time spent to make an item along a value stream. Its determined the production cycle time of all things considered

$$
\mathrm{TCT}=\mathrm{CT}_{1}+\mathrm{CT}_{2}+\mathrm{CT}_{3}+\ldots .+\mathrm{CT}_{\mathbf{n}}
$$

VA\% blends of significant value added and offered to clients along the supply chain. It is processed by the proportion of total cycle time to production lead time.

\section{VA $\%=$ TCT/PLT}

The assessed exhibitions of a value stream are examined further to create thoughts for enhancements in the current-state map. The improvement thoughts can be activated by other lean instruments, for example, disposal, blend, revision, and additionally rearrangements (ECRS), SMED, standard work, visual control and so forth.

\section{IV.IV EXPERIMENTAL RESULTS}

The experimental result ascertains the generic nature of the car business. The present worth stream of the car plant in Thailand is mapped. The proposed work of this paper is LSCM-VSM technique is utilized to decrease the generation time and squanders by the standard work and visual control. The present state guide is utilized to test the materials yet decreasing time is less so it moves the procedure to the future state map. The assessment results are appeared in table 3 and figure 4 .

Table 3 PLT and TCT Measurement of LSCM-VSM Method

\begin{tabular}{|l|l|l|}
\hline & Performance Measurement from Supplier to Customer Delivery \\
\hline & PLT(\%) & TCT $(\%)$ \\
\hline Existing-VSM & 84 & 16.2 \\
\hline Proposed-LSCM-VSM & 74 & 12.2 \\
\hline
\end{tabular}

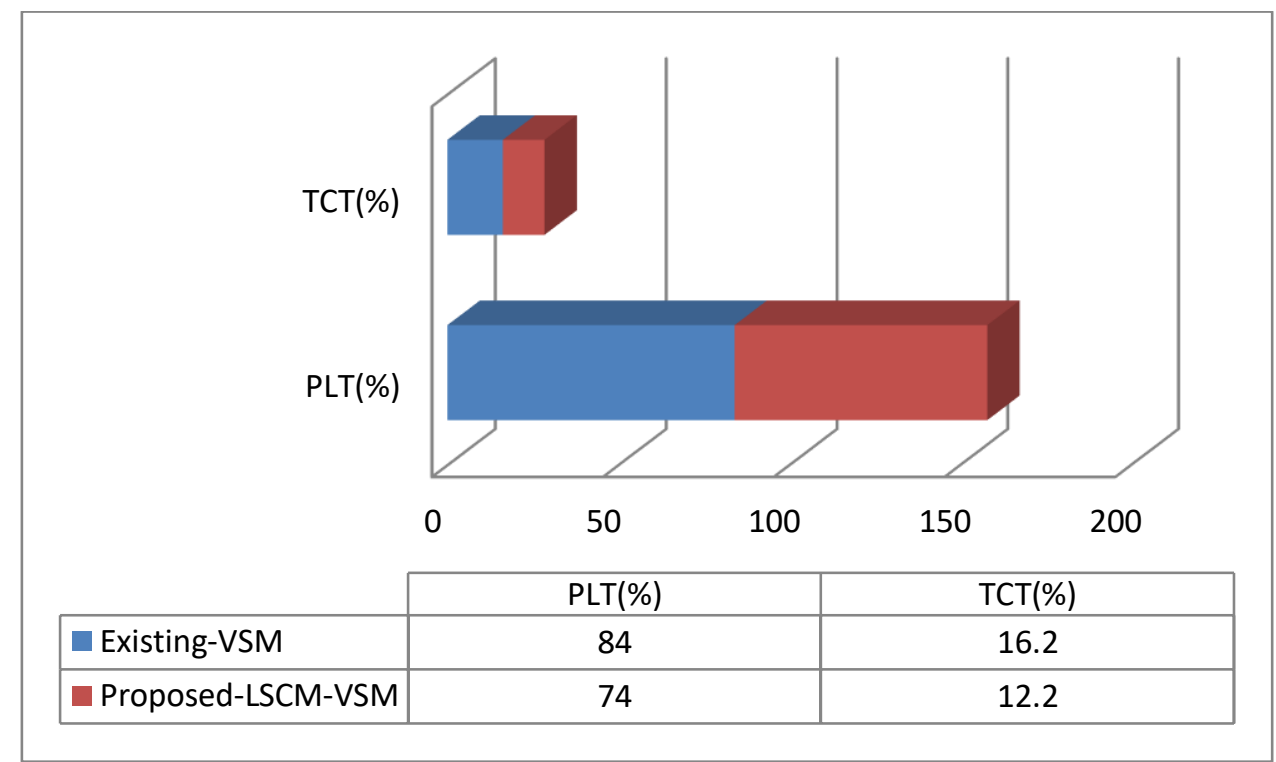

Figure 4 Analysis of PLT and TCT of LSCM-VSM Method

At that point as indicated by the improvement activities decrease in the current state, map wastage is showing just $56 \%$. So exchange to the future state map. The future state guide is fit for diminishing the lead time of material and item conveyances utilizing LSCM-VSM technique and lessen the trim unit 40 minutes not exactly VSM half and improved the squeezing unit to 5 minutes. Beneath table 4 and figure 5 demonstrates the specialty unit of present and future state guide and improvement rates

Table 4 Current State and Future State in Lean Supply Chain-VSM

\begin{tabular}{|l|l|l|l|l|}
\hline & Current State & Future State & $\begin{array}{l}\text { Exisitng } \\
\text { VSM(\%) }\end{array}$ & $\begin{array}{l}\text { Proposed } \\
\text { LSCM- VSM(\%) }\end{array}$ \\
\hline VA\% & 0.75 & 2.95 & 293.33 & 313.33 \\
\hline PLT(days) & 20days & 4 days & 80.00 & 90.00 \\
\hline TCT(min) & $216 \mathrm{~min}$ & $170 \mathrm{~min}$ & 21.30 & 25.30 \\
\hline
\end{tabular}




\section{Generic Supply Chain of Lean-Value Stream Mapping in Automotive Industry}

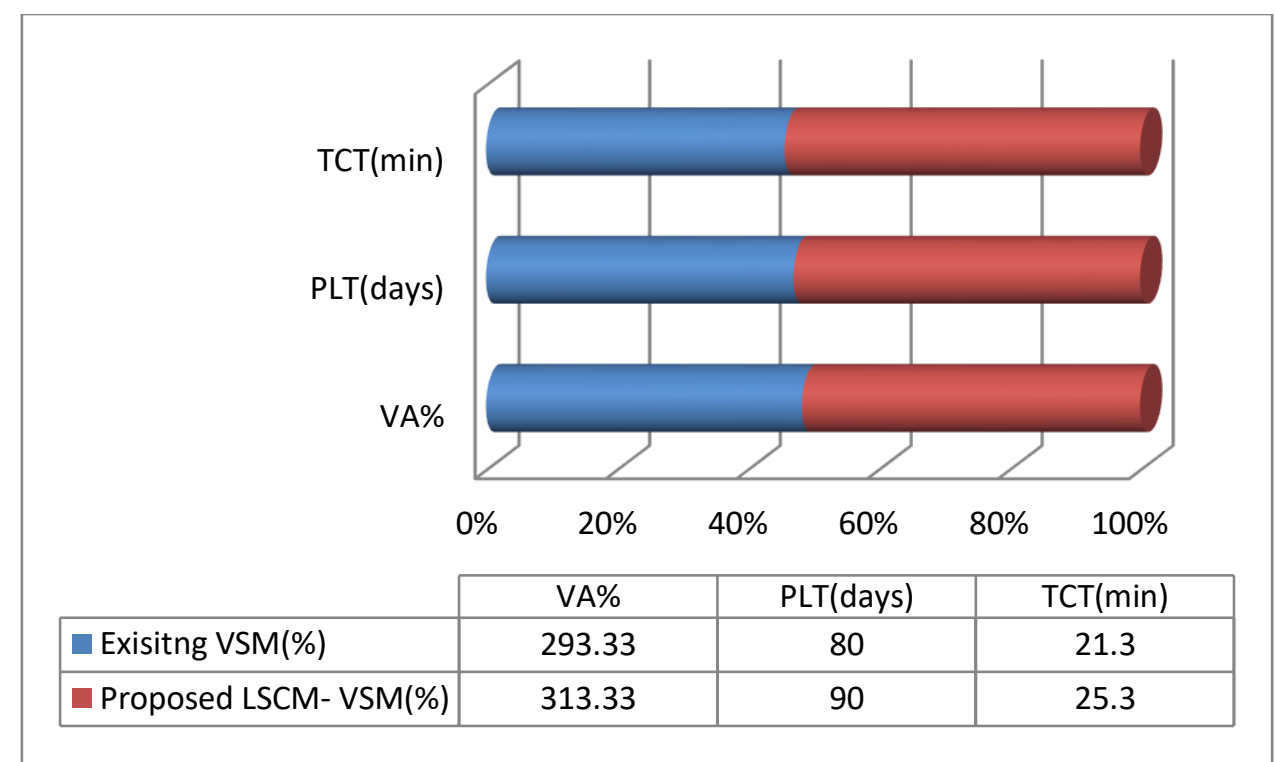

Figure 5 Analysis of Value-Added in Lean Supply Chain-VSM

\section{V.CONCLUSION}

This paper finishes up has demonstrated incredibly the LSCM-VSM device and this instrument is valuable to dispose of some waste in a cycle. The lean supply chain management is recognizing and dispensing with waste as estimated in time, stock and cost over the inventory network. It needs nonstop exertion and improvement. This technique is viewed as lean with supply chain a valuable to make accentuating adaptability estimated with lead time. The lean supply chain-value stream mapping comprises of the current state and future state map generation process. The data among clients and providers are mapped in the value stream. The principal objective of these two procedures is to the limited expense and augmented benefit. Consistent improvement in the value stream can make compensation to the upper range and past.

\section{REFERENCES}

1. Ana Julia Dal Forno, Fernando Augusto Pereira, Fernando Antonio Forcellini, Liane M. Kipper "Value Stream Mapping: a study about the problems and challenges found in the literature from the past 15 years about application of Lean tools" The International Journal of Advanced Manufacturing Technology Volume 72, Issue 5-8, pp 779$790,2014$.

2. Haifa Aby Nimeh,Ayman Bahjat Abdallah,Rateb Jalil sweis "Lean Supply chain management practices and performance:empirical evidence from manufacturing companies" Volume 7,Issue 1,2018,pp$1-15$.

3. Egon Müller,Timo Stock,Rainer Schillig "A method to generate energy value-streams in production and logistics in respect of timeand energy-consumption" Production Engineering,Volume 8,Issue 12,2014,pp 243-251.

4. Bhim Singh,Suresh K. GargSurrender K. Sharma "Value stream mapping: literature review and implications for Indian industry" The International Journal of Advanced Manufacturing Technology,2011, Volume 53, Issue 5-8, pp 799-809.

5. M. Ambe and J. A. Badenhorst-Weiss "Strategic supply chain framework for the automotive industry" African Journal of Business Management Vol. 4(10), pp. 2110-2120, 18 August, 2010

6. Boppana V. Chowdary,Damian George "Application of Flexible Lean Tools for Restructuring of Manufacturing Operations: A Case Study" Global Journal of Flexible Systems Management,2011, Volume 12, Issue 1-2, pp 1-8.

7. Lakri Siham, Bocquet Jean-Claude, Gregoire Laurent,Dallery Yves,Jemai Zied "Designing Supply Chain Performance Measurement and Management Systems: A Systemic Perspective"
2015 4th IEEE International Conference on Advanced logistics and Transport (ICALT),pp-212-216.

8. Ru-JenLin,Rong-HueiChen,Thi-HangNguyen "Green supply chain management performance in automobile manufacturing industry under uncertainty" Procedia - Social and Behavioral Sciences Volume 25, 2011, pp- 233-245

9. Souresh Bhattacharya "Supply Chain Management in Indian Automotive Industry : Complexities, Challenges and Way Ahead" 2014.

10. Guilherme Luz Tortorella "Lean Supply Chain Management: Empirical research on practices, contexts and performance" International Journal of Production Economics 2017 